\title{
Hepatocellular adenoma in a European flatfish (Limanda limanda): genetic alterations in laser-capture micro-dissected tissue and global transcriptomic approach
}

${ }^{\dagger a}$ Adélaïde Lerebours, ${ }^{\dagger}$ Emma Chapman, ${ }^{\ddagger}$ Brett P. Lyons, ${ }^{\ddagger}$ John P. Bignell, ${ }^{\ddagger}$ Grant D. Stentiford, and ${ }^{\dagger}$ Jeanette M. Rotchell*

${ }^{\dagger}$ School of Environmental Sciences, University of Hull, Cottingham Road, Hull, HU6 7RX, United Kingdom

${ }^{\ddagger}$ Centre for Environment, Fisheries and Aquaculture Science, Weymouth Laboratory, Barrack Road, The Nothe, Weymouth, Dorset DT4 8UB, United Kingdom

${ }^{a}$ Current address: School of Earth and Environmental Sciences, University of Portsmouth, Burnaby Building, Burnadt Road, Portsmouth PO1 3QL, United Kingdom

Keywords: fish, liver cancer, retinoblastoma gene, genetic changes, contaminants

\author{
Corresponding Author \\ *Jeanette M. Rotchell, phone number: +44 (0) 1482 465333, fax number: +44 (0) 1482 465458, e- \\ mail: J.Rotchell@Hull.ac.uk
}

Running title: Molecular changes in dab hepatocellular adenoma samples 


\begin{abstract}
Liver tumours in flatfish have been diagnosed using histopathology for decades to monitor the impacts of marine pollution. Here we describe the application of specific gene (retinoblastoma, $R b$ ) profiling in laser micro-dissected samples, and a suppression subtractive hybridization (SSH) approach to isolate differentially expressed genes in hepatocellular adenoma (HCA) samples from dab, Limanda limanda.

The $R b$ profiles from normal and HCA micro-dissected samples of fish from the North Sea showed no significant difference, and genotypic heterogeneity within defined histological phenotypes was observed. In the SSH, sequences associated with cell signalling, cell cycle, gene expression regulation, protein transport and protein degradation were isolated. These included upregulation of arrestin domain containing 3 (arrdc3), Rac-1 and tribbles, and down-regulation of ankyrin repeat/sterile alpha-motif domain-containing protein 1B-like (ANKS1B-like), c-fos, CDKN1B and RhoA-like sequences, previously implicated in mammalian HCA. This study offers new candidates involved in the underpinning molecular aetiology of fish liver tumour development.
\end{abstract}




\section{Introduction}

Liver pathologies of flatfish dab (Limanda limanda) English sole (Parophrys vetulus) and European flounder (Platichthys flesus) have been used internationally to monitor the effects of exposure to marine pollution since the 1980s (Malins et al., 1985; Vethaak and Reinallt, 1992; Stentiford et al., 2003; Lyons et al., 2015). Such lesions have been associated with exposure to anthropogenic contaminants such as polycyclic aromatic hydrocarbons (PAHs) (Malins et al., 1985; Vethaak and Reinallt, 1992). Dab possess both a similar histopathological tumour profile to humans (Stern and Zon, 2003) and homologs of human cancer genes such as ras and retinoblastoma $(R b)$, including mutational alterations of the $R b$ gene in tumour tissues (Du Corbier et al., 2005). In this respect, we have previously proposed that the dab hepatocellular tumour development could act as surrogate for cancer and the tumourigenesis process in human populations (Rotchell et al., 2009). Studies using this species also facilitate a better understanding of chemically-induced carcinogenesis in wild animals (Stentiford et al., 2005; Ward et al., 2006; Southam et al., 2008).

The histopathology of tumours and pre-tumours in dab liver are routinely diagnosed using a quality assured process involving histological tissue sections generated from wax-embedded samples (Feist et al., 2004). This diagnostic approach has recently been coupled with molecular analyses of tumour and surrounding normal tissue (Small et al., 2010). In addition, gross lesions and apparently normal tissues have been resected from the dab liver for molecular investigations such as genetic alterations of neoplastic associated genes (Du Corbier et al., 2005; Rotchell et al., 2009, Lerebours et al., 2014), transcriptomic (Small et al., 2010), proteomic (Stentiford et al., 2005) and metabolomic studies (Stentiford et al., 2005; Southam et al., 2008). Traditional microdissection and molecular analysis of populations of cells presents a challenge in that cellular heterogeneity within tissues samples may result in misleading findings (Cole et al., 1999; Sluka et al., 2008). Laser Capture-Microdissection (LCM) allows the ability to view and dissect target cells microscopically, thereby providing a direct link between a specific histopathological lesion and the molecular profile of that lesion (Gillespie et al., 2001). LCM has previously been applied to pathological studies in

(C) 2017. This manuscript version is made available under the CC-BY-NC-ND 4.0 license http://creativecommons.org/licenses/by-nc-nd/4.0/ 
aquatic organisms including fish (Vinas and Piferrer, 2008; Jorgensen et al., 2009; Kitahashi et al., 2009; Lerebours et al., 2013; Nowak et al., 2013; Leguen et al., 2015; Schaeck et al., 2016), crustaceans (Small et al., 2008), and cnidarians (Wiebring et al., 2010).

The study applies the LCM technique to facilitate an investigation of the $R b$ allele status in HCA and normal hepatocytes populations from North Sea sampled dab. $R b$ was selected on the basis that $R b$ mutations have previously been reported in dab liver tumour samples (Du Corbier et al., 2005; Lerebours et al., 2014). In parallel, a global transcriptomic approach using the suppressive subtractive hybridisation (SSH) method was used to analyse the differentially expressed genes between HCA-bearing liver and normal liver samples.

\section{Materials and Methods}

\subsection{Sample collection}

L. limanda were captured at UK Clean Seas Environmental Monitoring Programme (CSEMP) sites (Nicolaus et al., 2016) at the Dogger Bank, North Sea during July 2008 and 2009 using 30 min tows of a standard Granton trawl aboard the RV Cefas Endeavour. Upon landing, fish were immediately removed from the catch and placed into flow-through tanks containing aerated seawater. The sex, size (total length), weight (g), hepatosomatic index (HSI), gonadosomatic index (GSI), Fulton index Condition $(\mathrm{FC})\left(\mathrm{FC}=\mathrm{BW} / \mathrm{L}^{3} \times 100\right)$, and presence of external signs of disease were noted for each fish using methodology specified by the International Council for the Exploration of the Sea (Bucke et al., 1996). Following euthanasia, the body cavity was opened and the liver was assessed for the presence of macroscopic liver tumours according to the guidelines set out by Feist et al. (2004). For each fish, a standardised cross-section was obtained, placed into a pre-labelled histology cassette and fixed for $24 \mathrm{~h}$ in $10 \%$ neutral buffered formalin before transfer to 70\% industrial methylated spirit. An additional tissue cross-section was also obtained from the site immediately adjacent to the formalin-fixed sample. This sample was embedded in Optimum Cutting Temperature (OCT) media (RA Lamb, U.S.A.), frozen immediately in an iso-pentane cryobath and

(C) 2017. This manuscript version is made available under the CC-BY-NC-ND 4.0 license http://creativecommons.org/licenses/by-nc-nd/4.0/ 
then stored at $-80^{\circ} \mathrm{C}$ for subsequent laser-capture microscopy and molecular investigations. The sampling protocol allowed for a direct comparison of lesions in formalin fixed and cryopreserved samples of liver (Figure 1). The humane euthanasia of animals and sampling of their tissues, as detailed in this study, was undertaken in accordance with both national regulations and institutional policy.

\subsection{Sample processing}

Samples were processed according to Lerebours et al. (2013). Formalin-fixed paraffin embedded (FFPE) samples of liver were prepared by vacuum infiltration processing using standard protocols (Feist et al., 2004). Following embedding, sections were cut at 3-5 $\mu \mathrm{m}$ on a rotary microtome, and resulting tissue sections were mounted on glass slides before staining with haematoxylin and eosin (HE) (Figure 1). Glass slides were mounted with DePex and analysed by light microscopy using a Nikon Eclipse E800 microscope (Nikon, U. K.). Diagnoses of liver tumours followed guidelines set out by Feist et al. (2004).

Frozen samples were selected according to the presence and identification of lesions in the corresponding FFPE sections. OCT-embedded liver samples were transferred to a cryostat and acclimatised to $-20^{\circ} \mathrm{C}$. For each liver sample, two frozen sections were cut and collected onto an RNase clean glass slide. These sections were cut at 8-10 $\mu$ m which has previously shown to give efficient yields of high quality RNA without an excessive increase in tissue opacity, or chance of dissecting unwanted cells (Lerebours et al. 2013). Sections were subsequently stained according to a protocol adapted from Huang et al. (2002). Glass slides were immediately placed into $70 \%$ ethanol for 2-4 min and then rinsed in DEPC water. Mayer's hematoxylin stain was applied to the slide surface for 2 min followed by a rinse in DEPC-treated water. The slides were then incubated in Scott's bluing solution (Leica Microsystems, U. K.) for 30s followed by a rinse in DEPC water and a rinse in $70 \%$ ethanol. Eosin stain was applied for 45 s followed by dehydration in $95 \%$ ethanol for 30s, in $100 \%$ ethanol for $1 \mathrm{~min}$ and two baths of xylene of 1 min each. Frozen sections were 
screened to determine whether those lesions previously observed and classified within FFPE liver sections, were also present in the frozen sections (Figure 1). Specifically, the histopathological lesions of interest for the purposes of this study were controls (no abnormalities detected) and HCA. Upon identification, digital images of histological lesions were obtained using the Lucia G Screen Measurement System (Nikon UK Ltd., U.K.).

\subsection{Tissue microdissection}

LCMs were performed using the MMI Cellcut system (Molecular Machines and Industries, Switzerland). The system comprised an inverted microscope (Nikon) with a motorised stage attached to a computer with digital camera, panel monitor and a fixed ultraviolet (cold) laser source. Two to five frozen tissue sections (depending on the size of the lesion) were collected onto RNase clean LCM membrane slides from fish that displayed no abnormalities and from lesions of interest in fish displaying tumours. Membrane slides were immediately placed in $70 \%$ ethanol on ice prior to staining as described above, followed by allowing to air dry. During this process, interspersed frozen sections were also obtained and collected onto glass slides (in between those collected for LCM) and stained as described above for further comparative histological assessment. These additional sections allowed for the determination of the nature and localisation of the lesions whenever present in the fish analysed (due to the reduced image quality resulting from differential refractive light index of LCM membrane slides and no cover slip). Micro-dissected samples were captured following the laser cutting by mechanically lowering and raising an adhesive isolation cap (attached to a $0.5 \mathrm{~mL}$ collection tube) onto the membrane.

\section{3. $R b$ cDNA isolation and allele profiling}

The samples used for the $R b$ allele profiling were generated from laser microdissected samples cut from $8 \mu \mathrm{m}$ tissue sections (which differed from the classically dissected samples used for the SSH analysis described in section 2.4 below) (Figure 1).

(c) 2017. This manuscript version is made available under the CC-BY-NC-ND 4.0 license http://creativecommons.org/licenses/by-nc-nd/4.0/ 
Total RNAs from laser micro-dissected samples (using $n=7$ fish for HCA and $n=11$ fish for normal tissue $R b$ profile analysis) were extracted using the Absolutely RNA Microprep Kit (Stratagene, La Jolla, U.S.A.) according to the supplier's instructions. The optional DNase treatment was found to decrease the concentration of RNAs and was not suitable for our analyses. The elution step was repeated 2 times in a volume of $15 \mu \mathrm{L}$. The quality of RNA (the integrity of the 18 and $28 \mathrm{~S}$ ribosomal bands) for the largest sections was evaluated by electrophoresis on a $1 \%$ agarose-formaldehyde gel. First strand cDNAs were synthesized from $14 \mu \mathrm{L}$ of total RNA using the SuperScript ${ }^{\circledR}$ VILO $^{\mathrm{TM}}$ cDNA Synthesis Kit (Invitrogen Ltd, Paisley, U. K.) and according to the supplier's instructions. The duration of the transcription phase was $90 \mathrm{~min}$. Different lengths of $R b$ fragments were amplified in order to find the maximum length yielding a reliable sequencing resolution from microdissected samples. Following this, three overlapping parts of the coding sequence of the $R b$ cDNA: RbA1, RbA2 and $\mathrm{RbB}$, containing the region of functional importance, A and B, were amplified. Primer pairs used to amplify the region comprised between 620 and 1942 bp of the $R b$ cDNA (Accession number: AY973250) are described in Table 1. Next, 2 or $4 \mu \mathrm{L}$ of the reverse transcribed product was used as a template for subsequent PCR in a $25 \mu \mathrm{L}$ final volume using 2.5 units of the Expand High FidelityPLUS enzyme (Roche Diagnostics Ltd, West Sussex, U. K.), primers at a final concentration of $1 \mu \mathrm{M}$, and following the supplier's instructions. PCR reactions were performed according to the following programme: one cycle at $94^{\circ} \mathrm{C}$ for 2 min and 40 amplification cycles at $94^{\circ} \mathrm{C}$ for $30 \mathrm{~s}, 60^{\circ} \mathrm{C}(\mathrm{RbA} 1)$ or $65^{\circ} \mathrm{C}(\mathrm{RbA} 2$ and $\mathrm{RbB})$ for $30 \mathrm{~s}$, and $72^{\circ} \mathrm{C}$ for 1 min. $10 \mu \mathrm{L}$ of each PCR product were then sequenced commercially (Macrogen, Amsterdam, Netherlands).

\subsection{Suppression subtractive hybridisation (SSH)}

The SSH method was performed to facilitate the identification of genes differentially expressed between normal and HCA samples. Total RNAs from 8 normal fish and 8 HCA fish samples were extracted using the High Pure RNA Tissue kit (Roche Diagnostics Ltd, West Sussex,

(c) 2017. This manuscript version is made available under the CC-BY-NC-ND 4.0 license http://creativecommons.org/licenses/by-nc-nd/4.0/ 
UK) according to the supplier's instructions. RNA integrity was assessed by formaldehyde-agarose gel electrophoresis, and 8 samples from each treatment group (LCM-derived HCA and normal tissues respectively) were randomly selected and pooled together so two RNA pools were obtained with each sample having an equal concentration (312.5 ng). SMARTer PCR cDNA Synthesis Kit (Clontech, UK) reagents were used to generate cDNA and the Advantage 2 PCR Kit (Clontech, UK) was used for PCR reactions. The SSH procedure utilised the PCR-Select cDNA Subtraction Kit (Clontech, UK) with normal and HCA samples as the driver and tester respectively. The manufacturer's protocol was followed with the exception of phenol-chloroform extraction followed by purification using the NucleoSpin Gel and PCR Clean-up kit (Machery-Nagel, UK) as per manufacturer's instructions, which was substituted for column chromatography (to avoid the handling and use of phenol, a highly toxic chemical).

In order to generate sub-clones of varying sizes, the final PCR products resulting from SSH were run on a 1\% TBE agarose gel, stained post-run with ethidium bromide (Invitrogen, Paisley, UK), to generate smears which were then cut from the gel in 4 size-related pieces, each of which was purified with the NucleoSpin Gel and PCR Clean-up reagents (Machery-Nagel, UK). Subcloning with blue/white screening was performed both directly with the PCR products and also with gel-purified products using either the Original TA Cloning Kit with the pCR2.1 vector (Life Technologies, UK) or the TOPO TA Cloning Kit For Sequencing with the pCR4-TOPO vector (Life Technologies, UK) according to the manufacturer's protocols. The chemically competent cells used were TOP10 E. coli (Life Technologies, UK) and MAX Efficiency DH10B E.coli (Life Technologies, UK). White colonies were used to inoculate overnight liquid cultures which were screened for an insert using PCR with M13 primers. Plasmids containing inserts were purified with the Nucleospin Plasmid kit reagents (Machery-Nagel, UK) and sequenced (Macrogen Europe, Amsterdam, The Netherlands). Sequences were identified by protein and nucleotide BLAST searches (blastx and blastn) on the NCBI database with results giving E-value $>10^{-5}$ considered an appropriate match. 


\subsection{Quantitative real-time PCR validation of SSH results}

The following genes were selected for real-time PCR validation of the SSH results: Rasrelated C3 botulinum toxin substrate 1 (Rac1), proto-oncogene protein c-fos, and cyclin-dependent kinase inhibitor 1B (CDKN1B). The same RNAs ( $\mathrm{n}=8$ fish for each treatment) were used for RTPCR as were used for the SSH experiment in addition to 4 extra available RNAs selected from the normal group. Total RNA concentrations were measured using a Qubit 1.0 Fluorometer (Life Technologies, UK) and reagents. cDNA synthesis was performed using $1 \mu$ g total RNA and SuperScript ${ }^{\circledR}$ VILO cDNA Synthesis Kit reagents (Life Technologies, UK), followed by treatment with $0.5 \mu \mathrm{L}$ Ribonuclease $\mathrm{H}$ (RNase H) and its associated buffer (Thermo Fisher Scientific, Loughborough, UK) at $37^{\circ} \mathrm{C}$ for $45 \mathrm{~min}$.

RT-PCR reactions were performed on a CFX96 Real-Time PCR Detection System (BioRad, UK) in a total volume of $20 \mu \mathrm{L}$ consisting of $10 \mu \mathrm{L}$ FastStart Universal SYBR Green Master (Rox) (Roche, UK), $7 \mu \mathrm{L}$ molecular grade water (Fisher Scientific, UK), $2 \mu \mathrm{L}$ primer mix and $1 \mu \mathrm{L}$ template cDNA. Reactions were optimised using final primer concentrations of $100 \mathrm{nM}$ for reference genes and $300 \mathrm{nM}$ for genes of interest. Primer sequences and amplicon sizes are listed in Table 1. PCR products from each primer pair were sequenced to confirm target gene amplification. No-template cDNA controls were included with all runs to confirm the lack of amplification and melt peaks were also universally generated to confirm the absence of secondary products such as primer dimers and to demonstrate primer specificity. Primer efficiencies were calculated, according to the MIQE guidelines (Bustin et al., 2009), from at least four points over a 10X cDNA dilution range and were all within the $90 \%$ to $110 \%$ range (Table 1 ).

\subsection{Statistical analyses}

As part of the SSH optimisation, two genes were considered for their suitability as reference genes for this dataset: EF1 and $\alpha T U B$. Expression data was generated for each gene and stability across 
normal and HCA was tested. An unpaired T Test was performed in both cases using GraphPad InStat v3 (GraphPad Software Inc., La Jolla, USA), and although mean expression levels were stable between treatments for $\alpha T U B(p=0.1055)$, this was not the case for EF1 $(p=0.0127)$. As such, the three target genes were normalised to $\alpha T U B$ alone using the $2^{-\Delta \mathrm{Ct}}$ method (Livak and Schmittgen, 2001).

All subsequent data on the transcriptional response of the genes selected for the validation of the SSH results were tested for normality of the residuals and homogeneity of variance using GraphPad Instat v3 software. An unpaired t test was therefore performed for $c$ fos in order to test for significance between normal and HCA samples, whereas the Mann-Whitney Test was performed for Rac1 and CDKN1B. Statistical significance was accepted at the $p<0.05$ level. Any significant difference in biometric parameters (body length, body weight, and FC) or $R b$ genetic profiles between the HCA and normal samples was assessed using generalised linear models in R (R Development Core Team 2013).

\section{Results}

\subsection{Fish biometric data}

There were no significant differences between the length $(p=0.198)$, weight $(p=0.348)$ or the FC ( $p$ $=0.168$ ) between the (presumptively) normal fish and those with HCA (Table 2).

\section{2. $R \boldsymbol{b}$ mutational profile characterisation}

$R b$ genetic profiles were characterised in LCM-derived normal and HCA samples of North Sea dab. Four nucleotides were identified as changed in the $R b$ coding sequence at 996 bp (G to A), $1088 \mathrm{bp}$ ( $\mathrm{T}$ to $\mathrm{C}$ ), 1514 bp (G to T) and 1592 bp (G to T) leading to several different genetic profiles (Table 3). All of these changes occurred within the $R b$ sequence encoding the functionally important and conserved $\mathrm{A}$ and $\mathrm{B}$ domains. However, the $R b$ genetic profiles from normal and HCA samples showed no significant difference $(p=0.311)$.

(C) 2017. This manuscript version is made available under the CC-BY-NC-ND 4.0 license http://creativecommons.org/licenses/by-nc-nd/4.0/ 


\subsection{SSH analysis}

A number of differentially expressed genes, both up-regulated and down-regulated in HCA samples, were identified from the SSH experiment based on sequence similarity with other NCBI database sequences (Table 4). All dab sequences obtained here were also submitted to the database and were given accession numbers. Sequenced clones that generated no named matches, or matches below the E-value $10^{-5}$ cut-off, were not included.

\subsection{Validation of differentially expressed transcripts}

Relative expression levels of the 3 selected genes used for qPCR validation of SSH are shown in Figure 3. No significant differences between normal and HCA samples were detected for $R A C 1(p=0.0691), c-f o s(p=0.4893)$ or $C D K N 1 B(p=0.3837)$.

\section{Discussion}

Herein, we adopted two parallel approaches, $R b$ allele frequencies and global differential gene expression, to characterise molecular-level hallmarks of HCA development. In terms of $R b$ genetic profiles observed in the LCM derived samples, four nucleotide positions were altered in a manner similar to that previously identified in dab displaying liver hepatocellular carcinoma (HCC) and HCA lesions captured at sites of differing contaminant burdens in the North Sea (Lerebours et al., 2014). These four positions correspond to a region of functional importance of the $R b$ gene, leading to 8 genetic profiles previously identified (Lerebours et al., 2014) along with two new profiles both observed in samples dissected from fish captured at the North Dogger site (Table 3). In this study, albeit using a low sample number ( $\mathrm{n}=8$ fish), there is no apparent association between $R b$ profiles and HCA phenotype. This is in contrast to previous work (with a higher sample number of $n=165$ fish and control sampling sites in the English Channel), whereby $R b$ profiles were not randomly distributed and specific $R b$ profiles were associated with different phenotypes i.e. normal,

(C) 2017. This manuscript version is made available under the CC-BY-NC-ND 4.0 license http://creativecommons.org/licenses/by-nc-nd/4.0/ 
pre-neoplastic and neoplastic (Lerebours et al., 2014). Interestingly, $R b$ alleles previously associated with pre-neoplastic lesions (allele profiles $\mathrm{N}$ and $\mathrm{M}$, Lerebours et al., 2014) are observed within the 'normal' tissue samples analysed herein (Table 3). It is possible that a degree of phenotypic latency exists whereby molecular events take place before neoplastic alterations are observed. Conversely, profiles previously associated with normal histopathology (allele profile A, Lerebours et al., 2014), are observed within the 'HCA' samples analysed herein (Table 3). However, the dissection of the liver in the previous study may have included different populations of cells, normal and neoplastic. Similarly, the present study has shown several $R b$ allele genotypes obtained within a laser microdissected homogeneous population of cells. Additionally, other molecular events may have a role in the neoplastic development. Previous work conducted using dab samples has suggested the involvement of epigenetic mechanisms with a decrease in the global methylation in the development of hepatocellular neoplasm (Mirbahai et al., 2011). A combination of genetic and epigenetic changes may thus be involved in the neoplastic transformation of cells.

Using the parallel SSH approach, we generated libraries enriched for genes that varied between normal and HCA samples. A total of 82 successfully ligated plasmids were cloned, isolated and sequenced. The success rate for unique sequences obtained from the SSH experiment was 30.5\%, which is comparable to similar studies using non-model fish (8\%) (Urbatzka et al., 2013); lower relative to studies using fish model organisms (45-80\%) (Marchand et al., 2006; Luckenbach et al., 2008; Leguen et al., 2015); and an improvement compared with inveretebrate species such as molluscs (6-22\%) (Boutet et al., 2008; Craft et al., 2010; Ciocan et al., 2011). Duplicate sequences accounted for $27 \%$ of clones and the remaining $43 \%$ of clones could not be identified based on sequence similarities.

A number of transcripts of highlighted by the SSH approach were isolated (Table 4) and a few were selected for validation by qPCR. The qPCR approach failed to validate the SSH results, no significant difference in mRNA transcript expression was detected for any of the three genes (Rac1, c-fos, and CDKN1B) selected (Figure 3). This may be a result of low sample numbers or 
represent an actual lack of change in mRNA expression between the (presumptively) normal and

HCA liver samples and further analysis is required...*any comments on this please?

mRNA transcripts up-regulated in dab liver adenoma cells relative to normal hepatocytes

In HCA samples (Figure 2), sequences associated with cell signalling, cell cycle, gene expression regulation, protein transport and protein degradation were isolated (Table 4). Several genes involved in cell signalling were up-regulated in adenoma samples. For example, arrestin domain containing 3 (arrdc3) encodes a protein in mammals that plays a role in regulating cell surface expression of G protein-coupled and adrenergic receptors (Qi et al., 2014). Relevantly, arrdc3 up-regulation has been associated with the suppression of cancer cell proliferation, migration and invasion in breast tumour development (Draheim et al., 2010). Of the other cell signalling transcripts, Rac-1 encodes a G protein belonging to the Rho family of GTPases, which is also implicated in regulation of cancer cell migration (Oppelt et al., 2014). Up-regulation of Rac-1 has also previously been associated with progression of testicular and breast cancer in mammals (Kamai et al., 2004; Baugher et al., 2005). Calmodulin-like gene was also observed as up-regulated in HCA samples relative to the normal cell samples (Table 4). Calmodulin is a calcium binding messenger protein that is ubiquitous in the cytoplasm and mediates the control of several enzymes, ion channels, aquaporins and other proteins. Its up-regulation has been associated with parathyroid adenomas in mammals (Oldham et al., 1982), although there are no previous reports related to HCA development.

Tribbles homolog 1-like transcript has been identified as similarly up-regulated in the dab HCA samples. Tribbles was originally identified as a cell cycle regulator in mammals but is also considered as an adaptor in signalling pathways involved in tumour development (Yokoyama and Nakamura, 2011; Sakai et al., 2016). Relevantly, the mechanism of tribbles-induced action is thought to involve the ubiquitin-proteasome system, of which a 265 proteasome non-ATPase regulatory subunit-like transcript and a ubiquitin-conjugating enzyme E2 G1-like transcript, are

(C) 2017. This manuscript version is made available under the CC-BY-NC-ND 4.0 license http://creativecommons.org/licenses/by-nc-nd/4.0/ 
also among the up-regulated transcripts in the same cells sampled (Table 4). Of the remaining transcripts identified as up-regulated using the SSH approach, myosin light peptide is worthy of highlighting due to its possible contributory role in proliferation of breast cancer cells (Cui et al., 2010).

mRNA transcripts down-regulated in dab liver adenoma cells relative to normal hepatocytes

In the HCA samples (Figure 2), further sequences associated with cell signalling and cell cycle control were highlighted as down-regulated using the SSH approach relative to control hepatocytes (Table 4). Of particular note, Ankyrin (ANKS1B) encodes a tyrosine kinase protein involved signal transduction and apoptosis, and has been previously reported as down-regulated in smoking related clear cell renal carcinoma (Eckel-Passow et al., 2014). ANKS1B down-regulated expression has accordingly been suggested as a potential early warning detection marker of tumour development and prevention (Eckel-Passow et al., 2014). C6orf58 represents another signalling peptide which is involved in liver development and has relevantly been identified as mutated/dysfunctional in HCC (Li et al., 2011). Similarly, the RIMS2-like transcript encodes a protein that primarily tethers calcium channels to mediate synapsis in mammals (Kaeser et al., 2012), yet it has not previously been observed as having any role in tumour development.

Cell cycle control elements down-regulated in HCA cells compared with the normal hepatocytes includes: cyclin T2-like, CDKN1B and RhoA (Table 4). Cyclin T2 has been identified as interacting with cyclin dependent kinases (cdks) and the tumour suppressor gene retinoblastoma, each of which is involved in cell cycle progression (Simone et al., 2002). CDKN1B (also known as p27/kip1) expression has been reported as frequently down-regulated in many human cancers (Garcia-Fernandez et al., 2011). RhoA-like encodes a small GTPase protein in mammals and it’s activity is often lost in ras-mediated tumourigenesis (Zandvakili et al., 2015). Of the remaining down-regulated transcripts, $c$-Fos represents a transcription factor protein that also regulates cell 
signaling and proliferation in mammals but is usually up-regulated in tumourigenesis, including HCC (Yeun et al., 2001), in contrast to the findings here.

Several of the gene expressions observed in our dab HCA samples (using the SSH technique) are consistent with those reported previously in dab HCA tissue reported by Small et al. (2010). Using a flounder cDNA microarray approach with 6 individual dab, Small et al. (2010) identified multiple 60S ribosomal proteins, a complement component C8 protein, a Rag C (ras related) GTP binding protein and a liver metabolism related protein aldose reductase, as all being similarly differentially expressed in the HCA samples analysed. In contrast, vitellogenin was reported as highly up-regulated in (a) male dab samples dispalying HCA or HCC and (b) female dab displaying HCC but not in HCA. However, in this study (using mixed sex) a down-regulation was observed in HCA cell samples relative to microdissected normal hepatocytes.

This study on normal and neoplastic hepatocytes from dab has allowed (i) a comparison of $R b$ sequence profiles of cells displaying HCA versus normal ones and (ii) a comparison of the transcriptome. This study is the first to provide information specific to the neoplastic pathway of HCA in the flatfish dab and offers a number of differentially regulated genes for future analysis. The approach presented here adds to our understanding of the etiology of liver tumors in sentinel marine flatfish. This greater insight into the drivers of disease will further aid in the interpretation of field data where fish are increasingly beings used as sentinels of wider environmental health (Stentiford et al., 2010; Lang et al., 2015; Lyons et al., 2015) .

\section{Acknowledgements}

This work was conducted under the auspices of the Clean Seas Environmental Monitoring Programme (CSEMP) and funded by the Department for Environment, Food and Rural Affairs (Defra) under project SLA22G. 


\section{References}

Baugher, P. J., L. Krishnamoorthy, et al. (2005). "Rac1 and Rac3 isoform activation is involved in the invasive and metastatic phenotype of human breast cancer cells.” Breast Cancer Research 7:R965-974.

Boutet, I., D. Moraga, et al. (2008). “Characterisation of reproduction-specific genes in a marine bivalve mollusc: influence of maturation stage and sex on mRNA expression.” Gene 407: 130-138.

Bucke, D., Vethaak, A.D., Lang, T., and Mellergaard, S. 1996. Common diseases and parasites of fish in the North Atlantic: Training guide for identification. ICES Techniques in Marine Environmental Sciences, 19. 27 pp.

Bustin, S. A., V. Benes, et al. (2009). “The MIQE guidelines: minimum information for publication of quantitative real-time PCR experiments.” Clinical Chemistry 55: 611-22.

Ciocan, C. M., E. Cubero-Leon, et al. (2011). "Identification of reproduction-specific genes associated with maturation and estrogen exposure in a marine bivalve Mytilus edulis.”

PLoS One. 6(7):e22326. doi: 10.1371/journal.pone.0022326.

Cole, K. A., D. B. Krizman, et al. (1999). "The genetics of cancer - A 3D model." Nature Genetics 21(1 Suppl.): 38-41.

Craft, J. A., J. A. Gilbert, et al. (2010) "Pyrosequencing of Mytilus galloprovincialis cDNAs: tissue specific expression patterns. PLoS ONE 5: e8875.

Cui, W. J., Y. Liu, et al. (2010). "Myosin light chain kinase is responsible for high proliferative ability of breast cancer cells via anti-apoptosis involving p38 pathway.” Acta Pharmacologica Sinica 31:725-732.

Draheim, K. M., H. B. Chen, et al. (2010). “ARRDC3 suppresses breast cancer progression by negatively regulating integrin beta4.” Oncogene 29: 5032-5047. 
Du Corbier, F. A., G. D. Stentiford, et al. (2005). "Isolation of the retinoblastoma cDNA from the marine flatfish dab (Limanda limanda) and evidence of mutational alterations in liver tumors." Environmental Science and Technology 39(24): 9785-9790.

Eckel-Passow, J. E., D. J. Serie, et al. (2014). “ANKS1B is a smoking-related molecular alteration in clear cell renal cell carcinoma.” BiomedCentral Urology 14: 14.

Feist, S. W., T. Lang, et al. (2004). "Biological effects of contaminants: use of liver pathology of the European flatfish dab (Limanda limanda L.) and flounder (Platichthys flesus L.) for monitoring." ICES Techniques in Marine Environmental Sciences (38): 42.

Garcia-Fernandez, R. A., P. Garcia-Fernandez, et al. (2011). “Combined loss of p21 (waf1/cip1) and p27 (kip1) enhances tumorigenesis in mice.” Laboratory Investigation 91: 1634-1642.

Gillespie, J. W., M. Ahram, et al. (2001). "The role of tissue microdissection in cancer research." Cancer Journal 7(1): 32-39.

Jorgensen, A., J. E. Nielsen, et al. (2009). "Laser capture microdissection of gonads from juvenile zebrafish." Reproductive Biology and Endocrinology 7: 97.

Huang, L.E., V. Luzzi, et al. (2002). “Optimized tissue processing and staining for laser capture microdissection and nucleic acid retrieval.” Methods in Enzymology 356:49-62.

Kaeser, P. S., L. B. Deng, et al. (2012). "RIM genes differentially contribute to organizing presynaptic release sites.” Proceedings of the National Academy of Sciences U.S.A. 109: 11830-11835.

Kamai, T., T. Yamanishi, et al. (2004). "Overexpression of RhoA, Rac1, and cdc42 GTPases is associated with progression in testicular cancer.” Clinical Cancer Research 10: 4799-4805.

Kitahashi, T., S. Ogawa, et al. (2009). "Cloning and expression of kiss2 in the zebrafish and medaka." Endocrinology 150(2): 821-831.

Lang, T., S. W. Feist, et al. (2015). "Diseases of dab (Limanda limanda): Analysis and assessment of data on externally visible diseases, macroscopic liver neoplasms and liver histopathology 
in the North Sea, Baltic Sea and off Iceland.” Marine Environmental Research doi:10.1016/j.marenvres.2015.12.009.

Leguen, I., A. Le Cam, et al. (2015). “Transcriptomic analysis of trout gill ionocytes in fresh water and sea water using laser capture microdissection combined with microarray analysis.” PLoS ONE 10: e0139938. doi:10.1371/ journal.pone.0139938.

Lerebours, A., J. P. Bignell, et al. (2013). “Advanced diagnostics applied to fish liver tumours: relating pathology to underlying molecular aetiology.” Marine Pollution Bulletin 72: 94-98.

Lerebours, A., G. D. Stentiford, et al. (2014). "Genetic alterations and cancer formation in a European flatfish at sites of different contaminant burdens.” Environmental Science and Technology 48:10448-10455.

Li, M., H. Zhao, et al. (2011). "Inactivating mutations of the chromatin remodelling gene ARID2 in hepatocellular carcinoma.” Nature Genetics 43: 828-829.

Livak, K. J. and T. D. Schmittgen (2001). “Analysis of relative gene expression data using realtime quantitative PCR and the 2(T)(-Delta Delta C) method.” Methods 25: 402-408.

Luckenbach, J. A., D. B. Iliev, et al. (2008). “Identification of differentially expressed ovarian genes during primary and early secondary oocyte growth in coho salmon, Oncohynchus kisutch.” Reproductive Biology and Endocrinology 6: 2-18. doi:10.1186/1477-7827-6-2.

Lyons, B. P., G. D. Stentiford, et al. (2004). "DNA adduct analysis and histopathological biomarkers in European flounder (Platichthys flesus) sampled from UK estuaries." Mutation Research - Fundamental and Molecular Mechanisms of Mutagenesis 552(1-2): 177-186.

Lyons, B.P, J.P. Bignell, et al. (2015). “Determining good environmental status under the Marine Strategy Framework Directive: Case study for descriptor 8 (chemical contaminants).” Marine Environmental Research. doi:10.1016/j.marenvres.2015.12.010

Malins, D. C., M. M. Krahn, et al. (1985). "Toxic-chemicals in marine sediment and biota from Mukilteo, Washington - relationships with hepatic neoplasms and other hepatic-lesions in English Sole (Parophrys vetulus)." Journal of the National Cancer Institute 74(2): 487-494. 
Marchand, J., A. Tanguy, et al. (2006). "Molecular identification and expression of differentially regulated genes of the European flounder, Platichthys flesus, submitted to pesticide exposure.” Marine Biotechnology 8: 275-294. DOI: 10.1007/s10126-005-0099-3.

Mirbahai, L.; G. Yin, et al. (2011). "DNA methylation in liver tumorigenesis in fish from the environment.” Epigenetics 6(11): 1319-1333.

Nicolaus, E.E.M., S. R. Wright, et al. (2016). "Spatial and temporal analysis of the risks posed by polychlorinated biphenyl and metal contaminants in dab (Limanda limanda) collected from waters around England and Wales.” Marine Pollution Bulletin 112 (1): 399-405.

Nowak, B., K. Cadoret, et al. (2013). "Laser-capture dissection and immunohistochemistry reveals chloride and mucous expression levels in gills of seawater acclimated Atlantic salmon Salmo salar. Journal of Fish Biology 83: 1459-1467.

Oldham, S. B., L. G. Lipson, et al. (1982). "Presence of calmodulin in parathyroid adenomas.” Minerals and Electrolyte Metabolism 7:273-280.

Oppelt, A., E. M. Haugsten, et al. (2014). “PIKfyve, MTMR3 and their product PtdIns5P regulate cancer cell migration and invasion through activation of Rac1.” Biochemical Journal 461: 383-390.

Qi, S., M. O’Hayre, et al. (2014). “Structural and biochemical basis for ubiquitin ligase recruitment by arrestin-related domain-containing protein-3 (ARRDC3).” Journal of Biological Chemistry 289: 4743-4752.

Rotchell, J. M., F. A. du Corbier, et al. (2009). "A novel population health approach: using fish retinoblastoma gene profiles as a surrogate for humans." Comparative Biochemistry and Physiology - C Toxicology and Pharmacology 149(2): 134-140.

Sakai, S., C. Miyajima, et al. (2016). “Tribbles-related protein family members as regulators or substrates of the ubiquitin-proteasome system in cancer development.” Current Cancer Drug Treatments 16:147-156. 
Schaeck, M., W. DeSpiegelaere, et al. (2016). "Laser capture microdissection of intestinal tissue from sea bass larvae using an optimised RNA integrity assay and validated reference genes. Scientific Reports 6: 21092.

Simone, C., L. Bagella, et al. (2002). "Physical interaction between pRB and cdk9/cyclinT2 complex.” Oncogene 21: 4158-4165.

Sluka, P., L. O'Donnell, et al. (2008). "Application of laser-capture microdissection to analysis of gene expression in the testis." Progress in Histochemistry and Cytochemistry 42(4): 173-201.

Small, H. J., J. Sturve, et al. (2008). "Laser-assisted microdissection: A new tool for aquatic molecular parasitology." Diseases of Aquatic Organisms 82(2): 151-156.

Small, H. J., T. D. Williams, et al. (2010). "Gene expression analyses of hepatocellular adenoma and hepatocellular carcinoma from the marine flatfish Limanda Limanda." Diseases of Aquatic Organisms 88(2): 127-141.

Southam, A. D., J. M. Easton, et al. (2008). "Metabolic changes in flatfish hepatic tumours revealed by NMR-based metabolomics and metabolic correlation networks." Journal of Proteome Research 7(12): 5277-5285.

Stentiford, G. D., M. Longshaw, et al. (2003). "Histopathological biomarkers in estuarine fish species for the assessment of biological effects of contaminants." Marine Environmental Research 55(2): 137-159.

Stentiford, G. D., M. R. Viant, et al. (2005). "Liver tumors in wild flatfish: A histopathological, proteomic, and metabolomic study." OMICS A Journal of Integrative Biology 9(3): 281-299.

Stentiford, G. D., J. P. Bignell, et al. (2009). "Site-specific disease profiles in fish and their use in environmental monitoring." Marine Ecology Progress Series 381: 1-15.

Stentiford, G.D., J. P. Bignell, et al. (2010). "Effect of age on liver pathology and other diseases in flatfish: implications for assessment of marine ecological health status.” Marine Ecology Progress Series 411:215-230. 
Stern, H. M. and L. I. Zon (2003). "Cancer genetics and drug discovery in the zebrafish." Nature Reviews Cancer 3(7): 533-539.

Urbatzka, R., S. Galante-Oliveira, et al. (2013). “Tissue expression of PPAR-alpha isoforms in Scophthalmus maximus and transcriptional response of target genes in the heart after exposure to WY-14643.” Fish Physiology and Biochemistry 39:1043-1055. DOI 10.1007/s10695-012$9761-7$

Vethaak, A. D. and T. ap Rheinallt (1992). "Fish disease as a monitor for marine pollution: the case of the North Sea." Reviews in Fish Biology and Fisheries 2(1): 1-32.

Vinas, J. and F. Piferrer (2008). "Stage-specific gene expression during fish spermatogenesis as determined by laser-capture microdissection and quantitative-PCR in sea bass (Dicentrarchus labrax) gonads." Biology of Reproduction 79(4): 738-747.

Ward, D.G., Wei, W., et al. (2006). "Plasma proteome analysis reveals the geographical origin and liver tumor status of dab (Limanda limanda) from UK marine waters.” Environmental Science \& Technology 40: 4031-4036.

Wiebring, A., H. Helmholz, et al. (2010). “Separation and analysis of different types of nematocysts from Cyanea capillata (L.) medusae.” Hydrobiologia 645(1): 203-212.

Yokoyama, T., T. Nakamura (2011). “Tribbles in disease: signalling pathways important for cellular function and neoplastic transformation.” Cancer Science 102:1115-1122.

Yuen, M. F., P. C. Wu, et al. (2001). "Expression of c-myc, c-fos, and c-jun in hepatocellular carcinoma.” Cancer 91: 106-112.

Zandvakili, I., A. K. Davis, et al. (2015). "Loss of RhoA exacerbates, rather than dampens, oncogenic K-ras induced lung adenoma formation in mice.” PloS ONE 10: e0127923. 


\section{Figure and Table Legends}

Figure 1. Overview of the methods used to generate the samples used in the various analyses.

Figure 2. Image of a frozen section, collected on a glass slide, and showing a benign HCA. The arrow shows the edge of the HCA characterised by a compression of surrounding parenchyma. The HCA contains an increased number of hepatocytes between sinusoids.

Figure 3. Relative gene expression of normal and HCA samples for (A) Rac1, (B) c-fos, and (C) $C D K N 1 B$ with mean data plotted \pm SEM; $\mathrm{n}=8$ fish for normal and $\mathrm{n}=8$ fish for HCA.

Table 1. Primer pairs used for $R b$ mutational profile analysis and qPCR validation of SSH results.

Table 2. Biometric data for body length (L), body weight (BW), Fulton index Condition (FC)(FC = $B W / L^{3} \times 100$ ). Data are expressed as mean (SD), $n=7$ fish HCA samples and $n=11$ normal fish for LCM $R b$ profile analysis, $\mathrm{n}=8$ HCA and $\mathrm{n}=8$ normal fish for SSH analysis.

Table 3. $R b$ genetic profiles found in LCM-derived liver HCA cells and normal hepatocytes. ${ }^{*} R b$ profile as previously reported (Lerebours et al., 2014).

Table 4. Dab partial $c D N A$ sequences obtained from SSH which are either up-regulated or downregulated in HCA samples relative to normal hepatocytes, and their identifications based on sequence similarity obtained by NCBI database BLAST searches. 
Figure 1.

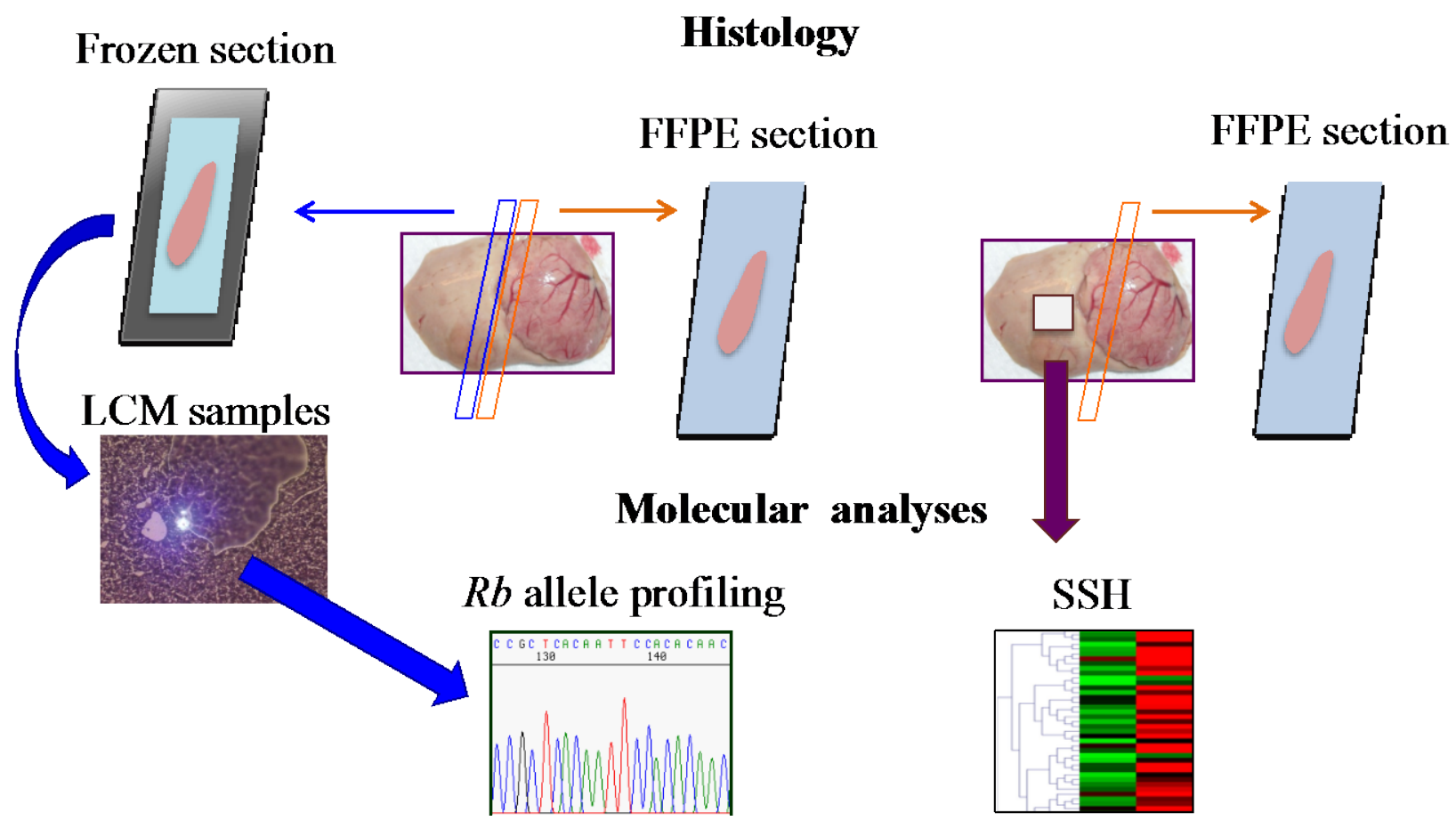


Figure 2.

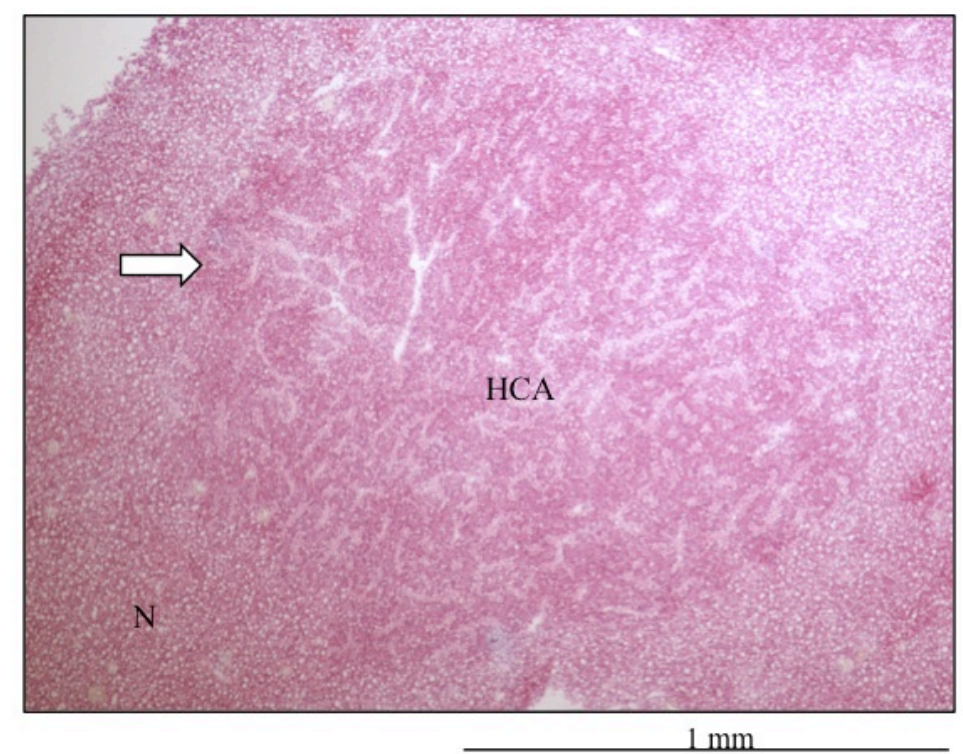


Figure 3.

Rac1

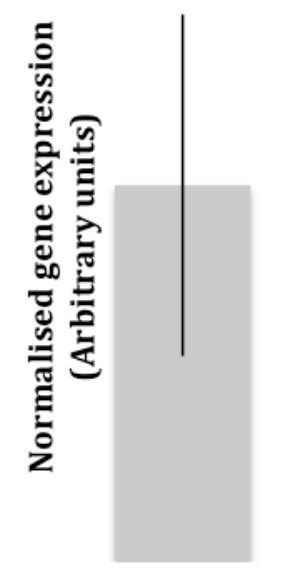

Normal

HCA

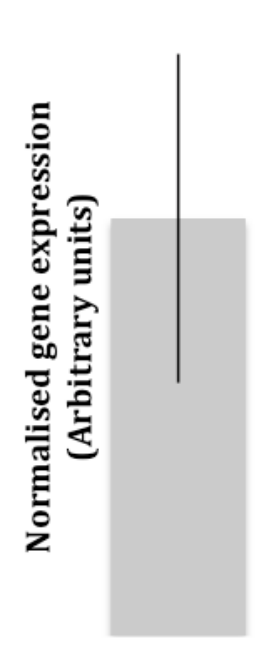

c-fos

Normal

HCA

\section{CDKNIB}

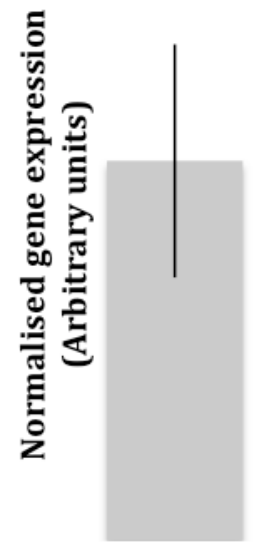

Normal

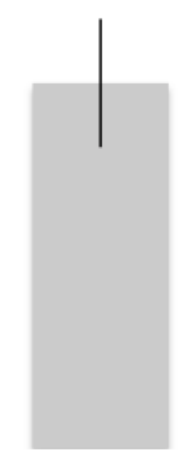

HCA

(c) 2017. This manuscript version is made available under the CC-BY-NC-ND 4.0 license http://creativecommons.org/licenses/by-nc-nd/4.0/ 
Table 1.

\begin{tabular}{|c|c|c|c|c|}
\hline Gene & Primer & Sequence 5'-3' & $\begin{array}{l}\text { Amplicon } \\
\text { size (bp) }\end{array}$ & $\begin{array}{l}\text { Amplification } \\
\text { efficiencies } \\
(\%) \\
\end{array}$ \\
\hline \multirow{2}{*}{ EF1 } & EF1_F1 & AGTGCGGAGGAATCGACAAG & \multirow{2}{*}{286} & \multirow{2}{*}{103.3} \\
\hline & EF1_R1 & CCTCGAACTCACCAACACC & & \\
\hline \multirow{2}{*}{$\alpha T U B$} & TUB_F1 & TCAATCACAGCCTCACTTCG & \multirow{2}{*}{197} & \multirow{2}{*}{94.2} \\
\hline & TUB_R1 & ATCTGATTGGCTGGCTCAAA & & \\
\hline \multirow{2}{*}{$c-f o s$} & cFos_F1 & TCGATGTGTCTTCAGAGCAA & \multirow{2}{*}{93} & \multirow{2}{*}{90.4} \\
\hline & cFos_R1 & TTTCTTTCACAAACAGCTCACA & & \\
\hline \multirow{2}{*}{$C D K N 1 B$} & CDKI_F3 & AGTCTCCTGAAGGACGAGGAG & \multirow{2}{*}{110} & \multirow{2}{*}{101.2} \\
\hline & CDKI_R3 & CACACTGCTACATTGACTGCTTT & & \\
\hline \multirow{2}{*}{ Rac1 } & Rac1_F3 & TGTATCACACTTCACTCACTGT & \multirow{2}{*}{102} & \multirow{2}{*}{102.2} \\
\hline & Rac1_R3 & GCTAGGCTTGCAGGGAGATT & & \\
\hline \multirow{2}{*}{$\begin{array}{l}R b(620-1070 \\
b p)\end{array}$} & RbA1_F & AATCAGAGCTGCCATGACCT & \multirow{2}{*}{450} & \\
\hline & RbA1_R & CCAGGGGAAACAAACATCTG & & \\
\hline \multirow{2}{*}{$\begin{array}{l}R b(983-1437 \\
b p)\end{array}$} & $R b$ A2_F & GGCAGCATATGGAGAGAGCGG & \multirow{2}{*}{454} & \\
\hline & RbA2_R & GAGCAGGCGGCTGGGTTGG & & \\
\hline \multirow{2}{*}{$\begin{array}{l}R b(1350-1942 \\
b p)\end{array}$} & $R b$ B_F & CGTCCGGGCCATCGTGTCTT & \multirow{2}{*}{592} & \\
\hline & $R b \mathrm{~B} \_\mathrm{R}$ & ACGTTGTTGCTGCCAGGCACA & & \\
\hline
\end{tabular}

(C) 2017. This manuscript version is made available under the CC-BY-NC-ND 4.0 license http://creativecommons.org/licenses/by-nc-nd/4.0/ 
Table 2.

\begin{tabular}{|c|c|c|c|c|c|c|}
\hline & \multicolumn{2}{|c|}{ Length (cm) } & \multicolumn{2}{c|}{ Body Weight (g) } & \multicolumn{2}{c|}{ FC } \\
\hline & Normal & HCA & Normal & HCA & Normal & HCA \\
\hline LCM & $22.8(1.2)$ & $23.1(3.0)$ & $106.5(23.3)$ & $127.1(67.4)$ & $0.9(0.1)$ & $1.0(0.1)$ \\
\hline SSH & $25.1(3.6)$ & $28.5(4.2)$ & $152.4(51.2)$ & $231.5(81.7)$ & $0.9(0.1)$ & $1.0(0.2)$ \\
\hline
\end{tabular}

This data needs to be broken down by sex.

We must also include GSI and HSI data for all fish 
Table 3.

\begin{tabular}{|c|c|c|c|c|c|}
\hline \multirow{2}{*}{ Sampling site (sex) } & \multicolumn{4}{|c|}{$R b$ genetic alterations } & \multirow{2}{*}{ Rb profile* } \\
\hline & 996bp & 1088bp & 1514bp & 1592bp & \\
\hline \multicolumn{6}{|c|}{$\begin{array}{l}\text { Hepatocellular adenoma (HCA) } n=7 \\
\text { fish }\end{array}$} \\
\hline North East Dogger (F) & $G$ & $\mathrm{~T}$ & $\mathrm{G}$ & $\mathrm{G}$ & $\mathrm{A}$ \\
\hline Central Dogger (M) & G & $\mathrm{T}$ & G & G & A \\
\hline North Dogger (M) & G & nd & G & G & nd \\
\hline North Dogger (F) & $\mathrm{G}$ & $\mathrm{T} / \mathrm{C}$ & $\mathrm{G} / \mathrm{T}$ & $\mathrm{G} / \mathrm{T}$ & B \\
\hline North Dogger (F) & G & nd & $\mathrm{T}$ & $\mathrm{T}$ & nd \\
\hline West Dogger (F) & $\mathrm{G}$ & $\mathrm{T} / \mathrm{C}$ & $\mathrm{T}$ & $\mathrm{T}$ & $\mathrm{O}$ \\
\hline West Dogger $(\mathrm{F})$ & G & $\mathrm{T} / \mathrm{C}$ & $\mathrm{G} / \mathrm{T}$ & $\mathrm{G} / \mathrm{T}$ & $\mathrm{B}$ \\
\hline \multicolumn{6}{|l|}{ Normal $n=11$ fish } \\
\hline North East Dogger (M) & $G$ & $\mathrm{~T} / \mathrm{C}$ & $\mathrm{G} / \mathrm{T}$ & $\mathrm{G} / \mathrm{T}$ & $\mathrm{B}$ \\
\hline North East Dogger (F) & G & $\mathrm{C}$ & $\mathrm{G} / \mathrm{T}$ & $\mathrm{G} / \mathrm{T}$ & $\mathrm{P}$ \\
\hline North East Dogger (F) & G & $\mathrm{T} / \mathrm{C}$ & G & $\mathrm{G} / \mathrm{T}$ & $\mathrm{N}$ \\
\hline North East Dogger (M) & G & $\mathrm{T} / \mathrm{C}$ & $\mathrm{G} / \mathrm{T}$ & $\mathrm{G} / \mathrm{T}$ & $\mathrm{B}$ \\
\hline North East Dogger (M) & G & $\mathrm{T} / \mathrm{C}$ & $\mathrm{G} / \mathrm{T}$ & $\mathrm{G} / \mathrm{T}$ & $\mathrm{B}$ \\
\hline North East Dogger (F) & G & $\mathrm{T} / \mathrm{C}$ & $\mathrm{G} / \mathrm{T}$ & $\mathrm{G} / \mathrm{T}$ & $\mathrm{B}$ \\
\hline Central Dogger $(\mathrm{F})$ & G & $\mathrm{T} / \mathrm{C}$ & G & $\mathrm{G} / \mathrm{T}$ & $\mathrm{N}$ \\
\hline Central Dogger (F) & G & $\mathrm{T}$ & G & G & A \\
\hline North Dogger (F) & G & $\mathrm{T} / \mathrm{C}$ & $\mathrm{G} / \mathrm{T}$ & $\mathrm{G} / \mathrm{T}$ & $\mathrm{B}$ \\
\hline North Dogger (F) & G & $\mathrm{C}$ & G & G & $\mathrm{M}$ \\
\hline West Dogger (F) & G & $\mathrm{T}$ & G & G & A \\
\hline
\end{tabular}

(c) 2017. This manuscript version is made available under the CC-BY-NC-ND 4.0 license http://creativecommons.org/licenses/by-nc-nd/4.0/ 
Table 4.

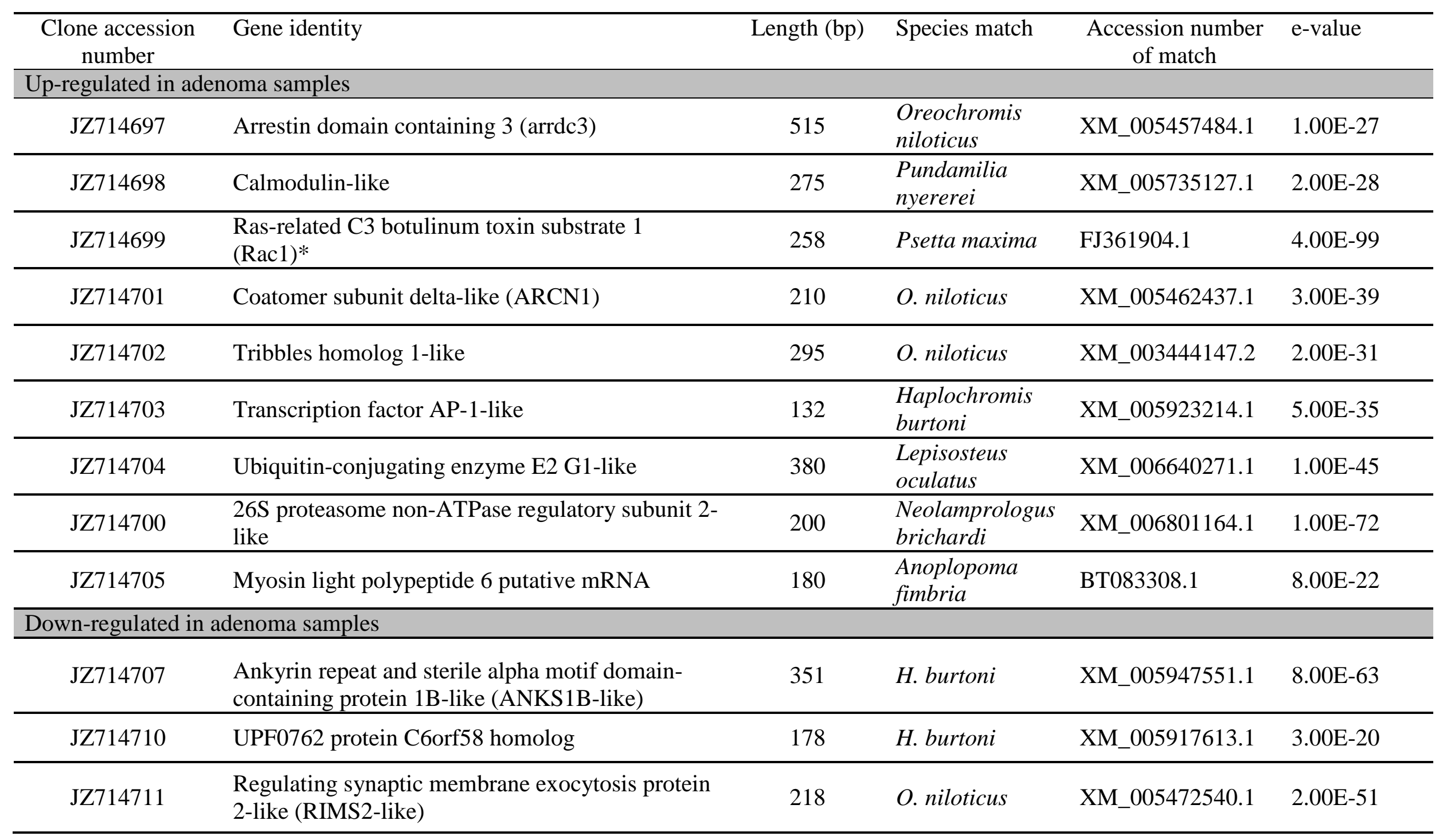




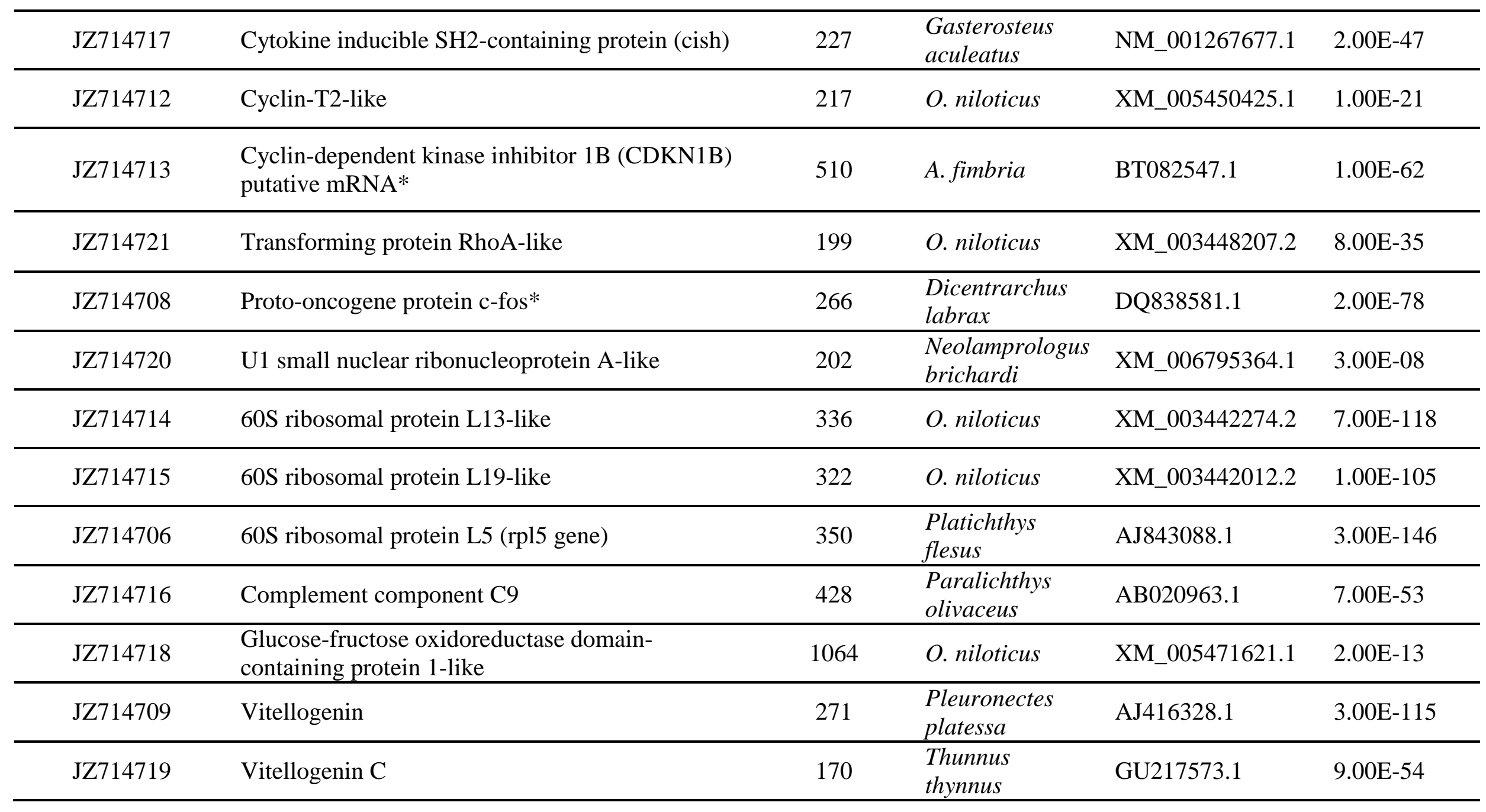


